\title{
Investigating the Impact of Teaching Based on Flipped Learning on the Academic Achievement of Sixth-Grade Students
}

Iranian Evolutionary and Educational Psychology Journal June 2020: 89-97 (C) University of Hormozgan Publication 2020 DOI: 10.29252/ieepj.2.2.89 http://ieepj.hormozgan.ac.ir

\section{S. Abdolhadi Samavi ${ }^{1}$, Hojatallah Javidi", Soltanali Kazemi ${ }^{3}$, Hossein Bagholi ${ }^{4}$}

\begin{abstract}
This study aimed to investigate the impact of flipped learning on the academic achievement of sixth-grade students. All sixth-grade students of Lamerd Elementary Schools in the academic year of 2019-2020 as the statistical population of this research and 40 sixth-grade students who were studying in one of the primary schools of Lamerd in the academic year of 2019-2020 as the statistical samples of the research were considered. The members of the present research sample were selected by the available sampling method. Sample members were assigned to two groups (control group 20 and experimental group 20). The two experimental and control groups were matched based on the variables of the previous academic year, the family's economic status, and the previous year's educational status. During the 10 sessions, the members of the experimental group received the same amount of training by the flipped training method and the control group, but in the form of traditional and normal training. The research method was quasi-experimental with pretest and posttest. Data analysis was performed using a one-way analysis of covariance and the Kolmogorov-Smirnov test was used to determine the normality of the data. The research findings showed that there was a significant difference between the two control and experimental groups $(F=19.83$ and $p=0.001)$. Thus, the effect of teaching based on flipped learning on the academic achievement of sixth-grade students was evaluated.
\end{abstract}

Keywords: teaching, flipped learning, academic achievement, sixth-grade students.

\section{Introduction}

In today's world, the issue of education and its effects on the behavior and education of students is considered as one of the vital challenges of humankind, so much so that many developed countries in the world have based their policy on growth in this field. Also, the main center of attention of scientists and scholars of educational sciences is the most optimal education for students, especially elementary school students, so that they can witness a prosperous and purposeful future, along with healthy citizens in various dimensions. Meanwhile, the issue of teaching methods and its effectiveness is one of the most controversial issues in the field of educational sciences and psychology, which, if not addressed well, will have detrimental effects on education, especially education in the sensitive elementary school.

Today, the new and active methods of "teaching" have attracted the attention of officials and teachers. In

1. PhD Student, Department of Psychology, Marvdasht Branch, Islamic Azad University, Marvdasht, Iran

2. Assistant Professor, Department of Psychology, Marvdasht Branch, Islamic Azad University, Marvdasht, Iran

*Corresponding author email: javidih97@gmail.com

3. Associate Professor, Department of Psychology, Marvdasht Branch, Islamic Azad University, Marvdasht, Iran

2. Assistant Professor, Department of Psychology, Marvdasht Branch, Islamic Azad University, Marvdasht, Iran 
these methods, the student, their interests, and abilities are in the center of attention, and the teacher tries to improve and strengthen the learners' abilities in listening skills, reading, writing, reasoning, comparing, adapting, analyzing, constructing, and creating creativity, and also provides classroom content in this regard (Akbari Sheldareie, Ghasempoor moghadam, \& Alizadeh, 2010).

One of the most important challenges in 21 st-century education is how to train learners who are prepared to deal with the changing society and the complexities of the information age. Extensive advances in science and technology, along with the rapid obsolescence of previous findings and information, require a kind of education in which students are constantly involved in the learning and problem-solving process and enjoy coping with challenges (Karimi, Nasr, \& Sharif, 2016).

Lage and Platt (2000) designed and implemented a method called "Flipped Classroom". They believe that in the flipped classroom, wind turbines receive their discussions through educational resources, and classroom time is devoted to more difficult concepts or the application of concepts in practice. They argued that flipped classroom means that what is traditionally said in the classroom is said outside the classroom and that extracurricular activities are transferred into the classroom. The use of special techniques such as educational multimedia and Internet networks has provided good opportunities to implement the flipped training method. This model seeks to address these challenges by allocating more time to the classroom for active learning methods and greater access to advanced technologies to support a combined learning approach (Kim, Kim, Khera, \& Getman, 2014).

In other words, the model addresses challenges such as classroom time management and the lack of face-toface interactions for completely different topics and audience composition. This approach can prepare learners for lectures based on their speed and schedule. Teachers, in turn, provide more explanation during class for immediate group and individual feedback from learners (Kakosimos, 2015).

Lage and Platt (2000) provide the simplest definition of a flipped classroom and include events that have traditionally been located inside the classroom and are now being moved out of the classroom, as well as events outside the classroom are transferred to the classroom; in fact, the flipped classroom is based on active learning and being learner-centered. Therefore, in a traditional classroom, the focus of classroom discussions is usually the teacher, and he or she controls all the conversations in the classroom. But the flipped class, the learner-centered classroom, is interactively managed by the teacher and the learners.

At a glance, the flipped class consists of two main parts, learning activities inside the classroom and individual training outside the classroom, which are illustrated in Figure 2-1, according to the topics discussed. As can be seen, the component of in-class learning includes inclusive-based learning theories and interactive activities, and the out-of-class education component includes teacher-centered and direct-learning theories (Kaviani, Liaghatdar, Zamani, \& Abediny, 2018).

Bahmani, Safaei Movahed, Hakimzadeh, Attaran, and Alavimoghadam (2017) have presented the explanation of the flipped class in a simple way in their article; flipped training transforms traditional teaching methods. In this way, the lessons are provided to the students online outside the classroom, and the homework that was previously done at home is solved in the classroom. Flipped education as a unique approach transforms the role of homework and classroom activities. In the traditional teaching method, students learned new lessons in the classroom through lectures and practiced them at home. In the flipped learning method, students learn content at home through video and practice skills in the classroom. This creates an active and interactive learning 
environment in which the teacher acts as a facilitator and guides students as they apply concepts and engage actively and collaboratively with the subject matter.

In the flipped classroom, the teacher already provides visual and auditory resources such as audio and video based on educational content. These resources are made available to students and they receive educational resources at home and outside the classroom. In the classroom, the teacher sets up homework assignments based on the educational resources previously seen by the students at home, and the students practice to deepen their learning in the classroom. In fact, because of the flipped process that occurs in such classes, they are referred to as the flipped class (Wolff \& Chan, 2016).

The flipped class is usually identified and implemented singly, but some experts have divided it into types. Analyzing the types helps to understand the concept of the flipped class. Traditional flipped class; in this class, learners watch instructional videos before class, then practice and practice in the classroom and the teacher helps learners understand the concepts. Flipped dominance finding class; in this model, learners work according to their speed and are evaluated after practicing with their classmates and the relevant instructor. If they score 80 percent or more in the assessment, they can move on to the next step, otherwise, they will have to re-read and re-test the material. Flipped classroom teaching to all groups; this pattern was proposed by Major, a Harvard physics professor. Students in the classroom answer conceptual questions individually and then try to convince the whole group with their answers. In this model, those who answer correctly can convince the whole group, and the learners are evaluated after practicing. Flipped problem-oriented class; in this model, learners find a problem, and when it is solved, the learning also occurs. In other words, learners learn from what happens in the process of solving the problem. In the process, watching the film helps the problem solving process. Question-oriented flipped class; this pattern is mostly used in science classes. Learners watch short films and class time is used to understand and discover the concept; learners then talk about the phenomena and events that took place. Watching a movie is effective in solving problems and misunderstandings. Reversible problem-oriented classes are among those flipped classes where learners are not expected to watch movies before class. According to the above division, the teaching method in the experimental research group of the present study can be placed in the category of the traditional flipped class (DeLozier \& Rhodes, 2017).

Although the flipped class is a new topic in education and training sciences, in Iran, very valuable research has been done on this issue, some examples of which are given as the latest findings in the field of flipped learning.

Nemati (2019) stated in a study entitled "Study of the Impact of Flipped Teaching-learning Method on the Development of Reading and Writing Skills of Non-Persian Language Learners" that the findings of the covariance test according to the e-learning materials prepared by the researcher and the illustrated book The main focus of the language learning process was in the flipped class, deep and sustainable learning, and the participation of $95 \%$ of learners, as evidenced by the teacher's objective evidence. This type of learning, under the influence of factors such as exploratory learning process strategies, independent and deep learning with appropriate time management, led to understanding, application, and analysis of lesson concepts.

In this regard, Piri, Sahebyar, and Sadollahi (2018), in a study entitled "The Effect of Flipped Class on Self-direction in Learning English" concluded that the flipped class has been able to have a significant effect on self-directional variability (except for the self-management component) in learning with the help of the 
covariate variable (pre-test). Also, the mean scores of students before and after the test in the experimental group were significantly different from each other; the average score of the self-directed learning curve of the students was higher through the flipped class.

Kaviani et al. (2018) also achieved the following results in a qualitative study entitled "Theoretical Framework of the Flipped Class: Drawing Points for Learning to Learn". Each of the basic components of the flipped class includes elements. For example, the in-class learning component includes inclusive-based learning theories and interactive activities, and the out-of-class education component includes teacher-centered learning theories and direct instruction. The flipped class responds to these challenges by transferring lectures outside the classroom and allocating class time to improving learners' understanding and learning activities to gain a deeper understanding of lesson concepts and debugging. Besides, inclusive learning activities include active learning, peer-to-peer learning, collaborative learning, problem-solving learning, and participatory learning that are consistent with the theoretical evidence of the flipped class.

Abroad, the leaders in this field have paved the way for further research and have discussed the subject of the flipped class under various research topics, some of which are listed below.

Chuang, Weng, and Chen (2018) conducted a study entitled "Concept, Design, and Implementation of a Flipped Class for Preschool and Internship Teachers to Run a Flipped Class.” They concluded that two key elements, pre-recorded interactive video lectures, and interactive learning activities, were identified for the first time in the flipped class.

Pickering and Roberts (2018), in a study titled "Flipped Class or Active Lecture", concluded that the teacher in the flipped class facilitates continuous learning and interaction by creating a space to assess the level of understanding and level of knowledge in the classroom and appropriate use of technology.

Bergmann and Sams (2014) in a study entitled "Study of the Effect of Flipped Class on Attracting Students" Attention and Their Progress", has concluded that the flipped class has a positive effect on attracting students' attention and academic progress and the flipped class can provide a good opportunity for students to learn by examining 19 studies; the classroom also increases student activity and prepares students for better learning. The present study, with a descriptive and analytical look, has tried to show the effect of teaching based on flipped learning on the academic achievement of sixth-grade students.

\section{Material and Method}

The statistical population of this study consisted of all sixth-grade elementary school students in Lamerd City in the 2019-2020 academic year. The population was estimated at 684 according to the Lamerd County Department of Education.

Samples of this research were selected by the available sampling method. A total of 40 subjects were randomly assigned to two groups of 20 individuals (experimental group and control group). The two experimental and control groups were matched based on the variables of the previous academic year, the family's economic status, and the previous year's educational status. In each group, based on the academic status of the previous year, an equal number of students from three very good, good, and acceptable academic indicators were assigned. In each group, based on the economic situation of the family, an equal number of three less educated, middle, and well-educated students were assigned. In each group, based on the educational situation of the previous year, an equal number of students from three very good, good, and acceptable educational indicators 
were assigned.

In this study, to evaluate the variable of academic achievement, students of two experimental and control groups of a pre-test were taken from the first five lessons of sixth-grade science, which has been prepared and arranged by the official primary education department of the city's education department. The validity of this test was determined by the content and using the opinion of experts and its reliability by the method of Kuder-Richardson. Then ten flipped learning-based training sessions were held for the experimental group and ten regular training sessions (traditional, lecture, with individual classroom atmosphere) for the control group, both at once every three days. A post-test (which was difficult to level with the pre-test) was then performed on all three groups. Post-test validity and content were also determined as the pre-test.

In this study, the central statistical indicators including mean and scatter indices were used as a standard deviation. Also, in the inferential statistics section, one-way analysis of covariance (ANCOVA) was used. It should be noted that the data were analyzed by SPSS software, version 16.

\section{Results}

Table 1 shows the mean and standard variable deviation of academic achievement for all subjects in the preand post-test stages. According to the findings in Table 1, the average score of academic achievement of all subjects in the pre-test stage was 13.28, which in the post-test stage has reached 14.65 with some growth. Also, the standard deviation of academic achievement for all subjects in the pre-test stage was 3.47 and 3.85 in the post-test stage.

Table 2 shows the mean and standard variable deviations of academic achievement for the subjects of the experimental group (flipped learning group) and control group (traditional and routine training group) in the pre-test and post-test stages. As can be seen in Table 2, the mean and standard variable deviation of academic achievement for the experimental group in the pretest stage was 14.47 and 2.32, respectively. After ten sessions of flipped learning-based training for this group, the average academic achievement in the post-test stage reached 17.35 and the standard deviation reached 1.77. The mean and standard deviation of the academic achievement variable for the control group in the pretest stage were 12.22 and 4.03, respectively. After ten sessions of traditional and routine training for this group, in the post-test stage, the average academic achievement has reached 12.57 and the standard deviation has reached 4.40.

Before analyzing the data related to the research hypothesis, they were examined to ensure that the data of this study estimated the underlying assumptions of the analysis of covariance. For this purpose, the assumptions of covariance analysis including linearity and homogeneity of regression of slope were investigated. Before examining the assumptions, the normality of the data was examined by the Shapiro-Wilk test. According to results, the significance level of the research variable was higher than 0.05 and as a result, the data related to this variable were normal.

In this study, the pre-test of academic achievement is considered as an auxiliary variable (covariate) and its post-test is considered as a dependent variable. The correlation coefficient between pre-test and post-test of academic achievement was 0.90 . According to the obtained coefficient, the assumption that the relationships between the auxiliary variable (covariate) and the dependent are linear has been achieved.

Table 2 shows the results of a one-way analysis of covariance in ANCOVA's text to compare post-test scores with the control of dependent pretests (academic achievement) in the experimental group and the control group. 
Table 1. Mean and standard deviation of academic achievement variable by experimental and control group

\begin{tabular}{|l|l|c|c|}
\hline Group & Statistical indicators & Pre-test & Post-test \\
\hline \multirow{2}{*}{ Experimental group } & Mean & 14.47 & 17.35 \\
\cline { 2 - 5 } Control group & SD & 2.32 & 1.77 \\
\hline \multirow{2}{*}{ Mean } & 12.22 & 12.57 \\
\cline { 2 - 5 } & SD & 4.03 & 4.40 \\
\hline
\end{tabular}

Table 2. Results of one-way analysis of covariance in ANCOVA's text to compare post-test scores with control of dependent variable pretests

\begin{tabular}{|l|l|l|l|l|l|l|l|}
\hline Effect & Dependent variable & SS & DF & MS & F & Sig. & Effect size \\
\hline Group & Academic achievement & 48.66 & 2 & 24.33 & 19.83 & 0.001 & 0.42 \\
\hline
\end{tabular}

The results of Table 2 show that one-way covariance analysis is significant in the variable of academic achievement $(\mathrm{F}=19.83$ and $\mathrm{p}=0.001)$. The present results indicate that there is a significant difference between the experimental and control groups in the dependent variable. According to the results of Tables 5 , the research hypothesis is confirmed and it can be said that; education based on flipped learning on the academic achievement of sixth-grade students in Lamerd City has had a positive and significant effect.

\section{Discussion}

The results of one-way covariance analysis and mean differences showed that education based on flipped learning on the academic achievement of sixth-grade elementary school students in Lamerd has had a positive and significant effect. The present study was consistent with the research of Nemati (2019), Kaviani et al. (2018), Nam (2019), Choi (2019), Eryilmaz and Cigdemoglu (2019) and Wang and Zhu (2019). Due to the novelty of the flipped training method on the one hand and the special importance of the variable of academic achievement on the other hand, many pieces of research have been or are being done in this field inside and outside the country.

In order to explain the presented findings, the researcher has stated the following reasons for the positive and significant effect of flipped education on academic progress using specialized texts:

Increasing the motivation for learning: The effectiveness of any curriculum depends largely on the learners and their willingness to learn. Some people have an internal motivation and participate in training automatically, but for others, it is necessary to create motivation, reward, and encouragement to get an education. Therefore, the design of the curriculum should be such that it creates continuity and motivation in the students so that education can be effective through it. Studies and research have shown that several factors are effective in motivating students to learn. For example, the use of new teaching methods, designing a new performance appraisal system, equipping schools with the necessary facilities and equipment, and expanding and improving the educational environment are among the factors that increase motivation and learning (Park, Shin, \& Jeon, 2019). One of the challenges that today's students are facing is the overuse of modern technology such as tablets, mobile phones, and cyberspace. By putting recent factors on the agenda, the flipped training method has been able to lead the world to the optimal learning challenge, not as a leisure technology, but as a means of teaching aids. Thus, flipped education has been able to use a motivating factor (the use of new technology) 
in the service of academic progress.

Efficient stress control and increased learning:Evidence suggests that one of the factors influencing learning and memory is stress and emotional events, the effects of which are well preserved. Physiological studies have shown that under basic conditions, the secretion of glucocorticoids is pulsed and dependent on the circadian cycle, but under stress conditions this pattern changes, and the secretion of these hormones increases (Ramadhani, Umam, Abdurrahman, \& Syazali, 2019).

In the part of the new method of flipped education, the student learns in the intimate and informal space of the home, he learns in safety and peace of mind, and when he determines, he learns away from the stress of formal space. This factor makes learning more efficient and long-lasting and will have a greater impact on the advancement of educational goals.

Providing purposeful homework and increased learning: Many studies have shown that the value students put in homework will also have a significant impact on their academic performance. Assessment of the task refers to the individual's beliefs about the importance of doing a particular task desirably. According to Linnenbrink and Pintrich (2003), motivation, interest, value, and emotion are important components of motivational engagement that directly affect students' learning and academic progress. In this model, personal interest is defined as the inner interest of students in a particular subject or task. The value component in this model is defined as value-benefit and refers to the benefit that a learner learns from learning content and content or doing a task.

Flipped classroom instruction requires learners to master basic knowledge before the classroom and to be able to develop high-level learning exercises during classroom time. Active Learning-Based Learning Activities are designed to promote learners in complex lesson discussions and develop participatory and interactive learning skills through peers and teachers, allowing teachers to make progress in the learning process (White et al., 2015). In flipped learning, out-of-class learning and high-level and purposeful homework are done in the classroom, and this feature provides an opportunity for the teacher to monitor the homework and control the way students practice. When this happens, the elements of students' forgetfulness will disappear and learning will happen in students.

In addition to the findings of the present study, there were some limitations, such as the limited research sample for male students, the difficulty of understanding the subjects of the research questionnaires by the subjects, and the use of the questionnaire as a self-report tool. Nowadays, the country's educational evaluation system is qualitative, but to perform more accurate statistical operations, the researcher was forced to use a quantitative evaluation method (scoring), which faced serious problems in providing feedback to students.

It is suggested that the findings of the present study, along with the explanation of the results, be provided to teachers, professors, and university instructors in the form of a booklet or article to become more familiar with the teaching method based on flipped learning. It is also suggested that to facilitate the implementation of the flipped education method, in-service courses called educational technology for teachers be held, and in those courses, the prerequisites for teaching this method to be taught. Finally, given the bitter experience of the world's education system in the 2019 and 2020 coronavirus pandemic crisis (as of this writing) and the forced closure of schools and universities and the need to implement more online training, it is recommended that educational institutions focus on implementing flipped learning-based learning as quickly as possible to deal with the current situation and similar situations. 


\section{Declaration of Conflicting Interests}

The author(s) declared no potential conflicts of interest with respect to the research, authorship, and/or publication of this article.

Funding: The author(s) received no financial support for the research, authorship, and/or publication of this article.

Acknowledgements: The authors would like to thank all the esteemed students for their sincere cooperation and companionship in this project.

\section{References}

Akbari Sheldareie, F., Ghasempoor moghadam, H., \& Alizadeh, F. (2010). New teaching-learning methods and their application in education. Tehran: Fartab Publication.

Bahmani, M., Safaei Movahed, S., Hakimzadeh, R., Attaran, M., \& Alavimoghadam, S. B. (2017). Evaluating the rate of engagement and academic achievement of high school students by using flipped classroom instruction. Applied Psychological Research Quarterly, 8(2), 35-49.

Bergmann, J., \& Sams, A. (2014). Flipped learning: Gateway to student engagement. International Society for Technology in Education.

Choi, M. S. (2019). A case study on flipped learning convergence in dental hygiene major: focusing on learning awareness and academic achievement. Journal of Convergence for Information Technology, 9(12), 252-263.

Chuang, H. H., Weng, C. Y., \& Chen, C. H. (2018). Which students benefit most from a flipped classroom approach to language learning? British Journal of Educational Technology, 49(1), 56-68.

DeLozier, S. J., \& Rhodes, M. G. (2017). Flipped classrooms: a review of key ideas and recommendations for practice. Educational Psychology Review, 29(1), 141-151.

Eryilmaz, M., \& Cigdemoglu, C. (2019). Individual flipped learning and cooperative flipped learning: their effects on students' performance, social, and computer anxiety. Interactive Learning Environments, 27(4), 432-442.

Kakosimos, K. E. (2015). Example of a micro-adaptive instruction methodology for the improvement of flipped-classrooms and adaptive-learning based on advanced blended-learning tools. Education for Chemical Engineers, 12, 1-11.

Karimi, S., Nasr, A. R., \& Sharif, M. (2016). University challenges in compiling of the suitable content with competencies of lifelong learner. Research in Curriculum Planning, 13(50), 14-26.

Kaviani, H., Liaghatdar, M., Zamani, B., \& Abediny, Y. (2018). A theoretical framework of flipped classroom: drawing pointers for learner-centered learning. Foundations of Education Studies, 7(2 (14) ), 59-78.

Kim, M. K., Kim, S. M., Khera, O., \& Getman, J. (2014). The experience of three flipped classrooms in an urban university: an exploration of design principles. The Internet and Higher Education, 22, 37-50.

Lage, M. J., \& Platt, G. (2000). The internet and the inverted classroom. Journal of Economic Education, 31(1).

Linnenbrink, E. A., \& Pintrich, P. R. (2003). The role of self-efficacy beliefs instudent engagement and learning intheclassroom. Reading \&Writing Quarterly, 19(2), 119-137.

Nam, H. (2019). The Effect of Flipped Learning Using Multimedia on Learners' Academic Achievement, Intercultural Competence, and Autonomy. Multimedia-Assisted Language Learning, 22(3), 84-101.

Nemati, M. (2019). Investigating the Effect of Flipped Teaching-Learning Method on Persian Language Learners' Reading and Writing Skills. Journal of Teaching Persian to Speakers of Other Languages, 8(2), 251-266. 
Park, B.-N., Shin, M.-K., \& Jeon, H.-J. (2019). Analysis about the effect of flipped learning based team activity. Journal of Convergence for Information Technology, 9(6), 44-51.

Pickering, J. D., \& Roberts, D. J. (2018). Flipped classroom or an active lecture? Clinical Anatomy, 31(1), 118-121.

Piri, M., Sahebyar, H., \& Sadollahi, A. (2018). The effect of flipped classroom on self-directed learning in English language classescourse. Journal of Technology Education, 12(3), 229-236.

Ramadhani, R., Umam, R., Abdurrahman, A., \& Syazali, M. (2019). The effect of flipped-problem based learning model integrated with LMS-google classroom for senior high school students. Journal for the Education of Gifted Young Scientists, 7(2), 137-158.

Wang, K., \& Zhu, C. (2019). MOOC-based flipped learning in higher education: students' participation, experience and learning performance. International Journal of Educational Technology in Higher Education, 16(1), 1-18.

White, C., McCollum, M., Bradley, E., Roy, P., Yoon, M., Martindale, J., \& Worden, M. K. (2015). Challenges to engaging medical students in a flipped classroom model. Medical Science Educator, 25(3), 219-222.

Wolff, L.-C., \& Chan, J. (2016). Flipped classrooms for legal education. Switzerland: Springer. 